\title{
Silicone heaven
}

Zhermack invite you to see the latest in silicone and alginate materials and enter in a draw for a weekend in Venice on stand N02. New this year is the upgraded Elite H-D+ impression system, the first addition silicone with nanotechnology which enhances sulcans detail. Also, on show will be the 'The Dental Advisor' award winning Occlufast Rock bite registration silicone.

As well as extra fast and chrome alginates, check out the non-gagging, colour changing alginate with an irresistible tropical mango flavour. Reader response number $\mathbf{8 3}$

\section{Talks programme}

Dental Protection will be presenting a series of talks each day at the exhibition.

The programme will cover a range of topics to assist both the general practitioner as well as more specific areas within dentistry. All the talks will qualify for verifiable CPD.

The talks will be held at the NEC in Griffin Suite 9 and with limited seating capacity available, individuals are advised to prebook a seat. For further information contact laura.miles@mps.org.uk.

Reader response number 84

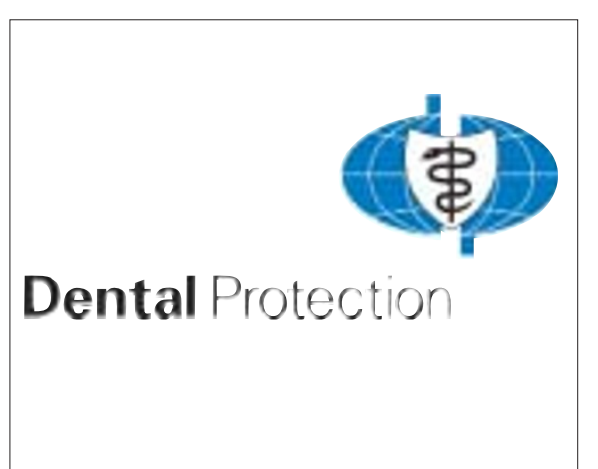

\section{Keep on smiling}

Smile-on stand M12a has a variety of courses and programmes available for the dental team.

Its latest offering, Clinical Audit Made Simple, was developed with Denplan to help dentists fulfil their NHS statutory requirements.

Smile-on will also be showing its NVQ for nurses training package. The Smile-on programme delivers the underpinning knowledge for the 14 units required for NVQ level 3.

There are also over 17 hours of verifiable online CPD. Courses cover clinical and business subjects.

Print the coupon from Smile-on's website, www.smile-on.com, to receive a $£ 5$ reduction on any of our learning products that you buy at the Show.

Reader response number 85

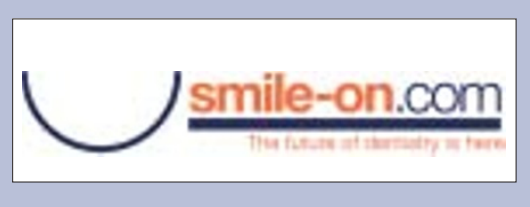

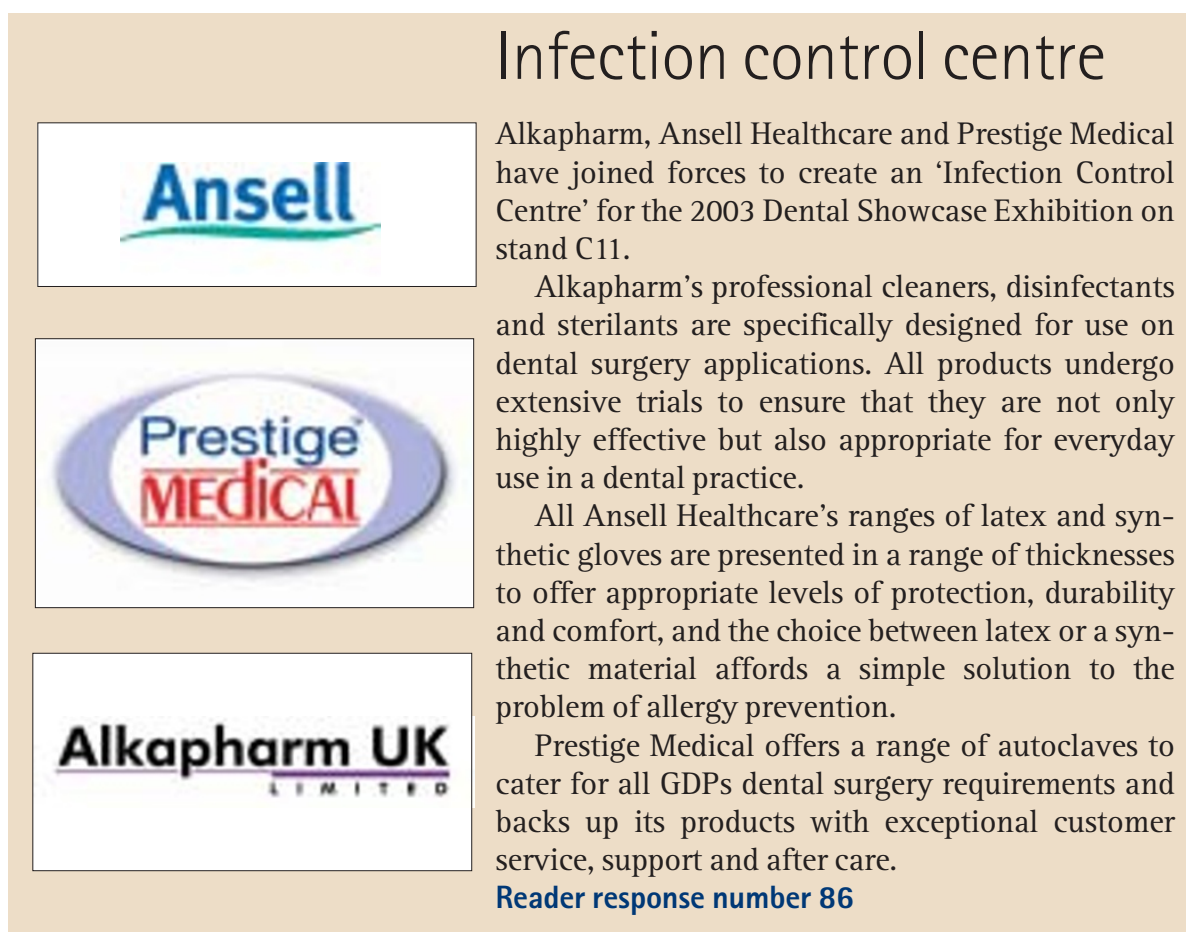

